\title{
Language development of Japanese twins in childhood based on maternal reports
}

\author{
Syuichi OOKI
}

Twins tend to lag behind singletons in their language development, though the causes of this are as yet unknown. Language development of twins is typically evaluated using the standards for the singletons in Japan, and the results often suggest that twins suffer from poor development. The present study was performed to resolve this situation. The subjects were 937 (maternal associations group) and 1092 (school applicants group) twin mothers and their twin children of known zygosity. Relative to general population norms, twins in the maternal associations group were about one to two months delayed in terms of age at first spoken word. Nevertheless, about $95 \%$ of twins have started speaking at least one word at 18 to 19 months, as singletons do. According to maternal reports from the school applicants group, monozygotic males, compared with singletons, showed the largest delay throughout childhood; this delay was partly attributed to the effect of 'twin language'. Language development was more similar to that of monozygotic pairs than that of dizygotic pairs. In conclusion, the results of present study suggested that language development of twins partly differ from that of singletons and that estimation of language development specifically for twins are needed.

Key words : twins, language development, database, zygosity, twin language

\section{Introduction}

In Japan, as in other developed countries, multiple birth rates have been increasing. Higher rates of twin births since 1987 have been attributed to both the higher proportion of mothers treated with ovulation-inducing hormones and to the increasing use of in-vitro fertilization (Imaizumi and Nonaka, 1997). Under such circumstances, there is an increasing need to provide appropriate information to parents and nursing staff on the biological characteristics of twins, such as their intrauterine growth, physical growth after birth, and motor and language de- velopment.

Since the classical study performed by Day (1932), it has become a well known fact that twins tend to lag behind singletons in terms of language development (Tomasello et al., 1986; Hay et al., 1987; Akerman, 1987; Akerman and Thomassen, 1991, 1992; Thorpe et al., 2003; Rutter et al., 2003), although the causes of this delay are unknown and appear to be complex. Because there are no large scale data to show this tendency directly in Japan, language development of twins must be evaluated using the standards for the general population, that is, essentially the standards for singletons. As a result, many twins 
may be regarded as showing poor development, causing their parents much anxiety and concern. In general, the professional advisors for the growth and development of children, such as pediatricians and public health nurses, do not have adequate information to answer the questions concerning these children's language development that are asked by the parents. To resolve this situation, it is essential to obtain objective data on language development based on a large sample of Japanese twins.

In Japan, the developmental norm for the 'age at first spoken word' was presented together with other milestones regarding motor development in childhood by the Ministry of Health, Labor and Welfare. The purpose of the present study was to compare language development of twins with that of the general population. Moreover, some features of language development reported by mothers, which were unique to twins, were also analyzed for practical use in maternal and child health care for multiples.

\section{Methods}

\section{Subjects and Outline of Data Collection}

Many countries, including some in Asia, have constructed or have been constructing large population-based twin registries, whereas no systematic twin registry exists in Japan (Ooki et al., 2003). There are mainly three types of data sources regarding multiples in Japan: vital statistics, data from large hospitals, and a volunteerbased database. The volunteer-based database covers the gap between vital statistics and hospital data, and is larger than and more unbiased than hospital data and contains more detailed information than do vital statistics. In addition, data regarding the condition of the twins after birth can be collected in the volunteer database; this is data that both vital statistics and hospital data seldom contain. This background information represents continuous data on twins in childhood and on their families that the author has been gathering for the purpose of contributing to twins' health care and to the genetic epidemiologic study of twins and their families (Ooki and Yokoyama, 2003, 2004; Ooki et al., 2004). The data used in this study were a portion of this body of data.

The present sample consisted of two independent groups of subjects. A detailed description of both groups is given in Table 1 . The first group of subjects consisted of 937 mothers from the several associations for the parents of multiples throughout Japan (maternal associations group). Birth years ranged from 1986 to 2002. The data from this group was gathered in 2002 and 2003 intensively. The age of twins at data collection was from 0 to 15 years. The second group of subjects consisted of 1092 mothers and their twin children living in the Tokyo metropolitan area, with all of the twins attending secondary school attached to the faculty of education of the University of Tokyo from 1981 to 2003 (school applicants group). Birth years ranged from 1968 to 1991. The present style of systematic data collection has been performed since 1981. Twins were all 11 or 12 years of age at data collection. No subjects in both groups were severely retarded from the medical point of view with regard to physical growth and motor and language development at data collection.

Information regarding family structure, obstetrical findings on the mothers, the physical growth of twins, zygosity, and motor, language, and mental development of twins, the medical history of twins and parents, behavioral problems of twins, and others were gathered as core items from both groups by means of mailed or personally distributed questionnaires. Since 
Table 1 Basic Characteristics of Present Data

\begin{tabular}{|c|c|c|c|}
\hline & & Maternal associations group & School applicants group \\
\hline \multicolumn{2}{|l|}{$\mathrm{n}$} & 937 pairs & 1092 pairs \\
\hline \multicolumn{2}{|c|}{ method of data collection } & mailed questionnaire & $\begin{array}{l}\text { handed questionnaire and } \\
\text { interview }\end{array}$ \\
\hline \multicolumn{2}{|c|}{ year of data collection } & $2002-2003$ & $1981-2003$ \\
\hline \multicolumn{2}{|c|}{ district } & all around Japan & Tokyo metropolitan area \\
\hline \multicolumn{2}{|c|}{ birth year of twins } & $\begin{array}{l}1986-2002 \\
\text { (mean 1995, SD 3.8) }\end{array}$ & $\begin{array}{l}1968-1991 \\
\text { (mean 1978, SD 6.4) }\end{array}$ \\
\hline \multicolumn{2}{|c|}{ age of twins at data collection } & $\begin{array}{l}0-15 \text { years } \\
(\text { mean } 6.0, \mathrm{SD} 3.8, \text { median } 5)\end{array}$ & $\begin{array}{l}164 \text { pairs at } 11 \text { years and } \\
928 \text { pairs at } 12 \text { years }\end{array}$ \\
\hline \multirow[t]{2}{*}{ sex of twins } & male individuals & 971 & 1026 \\
\hline & female individuals & 903 & 1158 \\
\hline \multirow[t]{11}{*}{ zygosity } & methods of classification & zygosity questionnaire & $\begin{array}{l}\text { zygosity questionnaire } \\
\text { and/or DNA/genetic } \\
\text { markers }\end{array}$ \\
\hline & monozygotic (male-male) & 230 & 327 \\
\hline & monozygotic (female-female) & 203 & 399 \\
\hline & dizygotic (male-male) & 95 & 75 \\
\hline & dizygotic (female-female) & 108 & 66 \\
\hline & dizygotic (male-female) & 95 & 68 \\
\hline & dizygotic (female-male) & 112 & 56 \\
\hline & suspended (male-male) & 46 & 30 \\
\hline & suspended (female-female) & 31 & 36 \\
\hline & insufficient information (male-male) & 11 & 19 \\
\hline & insufficient information (female-female) & 6 & 16 \\
\hline \multicolumn{2}{|c|}{ questions as to language development } & $\begin{array}{l}\text { age at first spoken word } \\
\text { (by month) }\end{array}$ & $\begin{array}{l}\text { maternal subjective esti- } \\
\text { mation of their twins' } \\
\text { language development } \\
\text { throughout childhood }\end{array}$ \\
\hline
\end{tabular}

SD: Standard Deviation

these data were gathered not in the same periods, each item of the questions was not necessarily in the same format. For the school applicants group, one of the parents of each applicant, usually the mother, participated in a medical interview by two or three interviewers (the author being an interviewer from 1987 on) in which their responses to the questionnaire were checked carefully.

\section{Zygosity classification}

The zygosity of twins was determined mainly by means of a zygosity questionnaire (Ooki and Asaka, 2004), which is used widely in Japan. Mothers of both groups answered this zygosity questionnaire. Zygosity diagnoses using many DNA/genetic markers were performed in addition to the zygosity questionnaire for those twin pairs of the school applicants group who were admitted to the school (Ooki and Yokoyama, 2003). Zygosity determined by many DNA/genetic markers occurred prior to that determined by questionnaire. When zygosity determination by DNA/genetic markers was regarded as the gold standard, the accuracy of the zygosity questionnaire was $97.5 \%$ (199/204), though $8.9 \%$ (20/224) of pairs were not classified by questionnaire (Ooki and Asaka, 2004).

In total, 726 monozygotic (MZ) and 265 dizygotic (DZ) with 101 unclassified zygosity were 
determined for the school applicants group, and $433 \mathrm{MZ}$ and $410 \mathrm{DZ}$ with 94 unclassified zygosity were determined for the maternal associations group. This is one of the advantageous features of present data, as zygosity diagnosis of the same-sex twins is seldom performed in Japan.

\section{Questions as to language development and statistical analyses for the maternal associations group}

With regard to language development, the age at first spoken word was asked about by month. The present data was based on maternal retrospective reports according to the age of the twins at data collection. The data were mainly based on their memory or records in the "Maternal and Child Health Handbook". The growth data of children based on mass examinations in Japan are usually recorded in this Handbook, and the author advised the mothers to refer to these records when completing the questionnaire. If mothers could not remember events in their children's language development, the author recommended in the questionnaire that they should not necessarily complete questionnaire using incorrect answers.

In analysis, only those twins whose first spoken word occurred between 6 to 25 months were used in consideration with the growth standards presented by the Ministry of Health, Labor and Welfare (Takaishi et al., 1992; Kato et al., 2002). Data were missing for 636 twins of varying ages out of 1874 (937 pairs). Of 1238 answers, 31 were excluded because these data did not meet the above mentioned inclusion criteria. Therefore, 1207 answers, representing 614 males and 593 females, were used in analysis.

In the statistical calculation, the following adjustment was performed. Because the data answered by mothers was by month and contained about 30 days internal, 0.5 months was added assuming that the age at first spoken word in each month was normally distributed.

First, factors that affect the age at first spoken word of twins were confirmed by stepwise regression analysis, with a threshold significance level of 0.15 . The variables considered were sex, birth order of twins (first-born or second-born), birth complications of mothers or twins, gestational age (weeks), maternal and paternal age at twin birth, parity, zygosity ( $\mathrm{MZ}$ or $\mathrm{DZ}$ ), birth weight $(\mathrm{g})$, motor development (age at sitting with head steady), and age of twins at data collection. Birth complications of mothers or twins included, for example, placenta previa, placental abruption, coiling of the umbilical cord, neonatal asphyxia, twin-to-twin transfusion syndrome, and so on. Age at sitting with head steady was limited between one and nine months with reference to the norms presented by the Ministry of Health, Labor and Welfare (Takaishi et al., 1992; Kato et al., 2002). Age of twins at data collection has an inverse relationship with the birth year of twins.

For qualitative variables, the following codes were used: sex, female: 0 , male: 1 ; birth order, first-born: 1, second-born: 0 ; birth complications, yes: 1 , no: 0 , zygosity, MZ: 0, DZ: 1; parity, primiparity: 0, multiparity: 1 .

Next, cumulative frequency distribution regarding the age at first spoken word was calculated, and compared with those presented by the Ministry of Health, Labor and Welfare (Takaishi et al., 1992; Kato et al., 2002), wherein the values of cumulative relative frequency for selected months after birth were presented. Standards of the general population in 1990 and 2000 were used considering twins' birth year.

Cumulative frequency distribution regarding the age at first spoken word according to sex 
was also calculated. The means, standard deviations, and median of the age at first spoken word were calculated according to sex and zygosity.

\section{Questions as to language development} and statistical analyses for the school applicants group

For the school applicants group, the following two questions regarding maternal subjective estimation of their twins' language development were asked. The first question was, 'In childhood, was your twin children's language development delayed compared with that of contemporary singletons?' The mothers selected one answer from following three items. 1, not delayed; 2 , slightly delayed; 3 , considerably delayed. The second question was, 'To what degree was the language development of your twin children alike during childhood?'. The mothers selected one answer from following three items. 1, no difference (very similar); 2 , slight difference; 3 , clear difference. Maternal subjective estimation of their twins' language development was analyzed according to sex and zygosity.

All statistical analyses were performed using $\mathrm{SAS}^{\circledR}$ for Windows (1997). Smoothing of the cu- mulative frequency distribution was performed using the PROC TRANSREG program, specifying the "pspline" model.

\section{Ethical issues}

The mothers in the maternal associations group cooperated voluntarily in this research, mainly through the president of their associations. It was clearly mentioned in the questionnaire that only statistical analysis was performed on the data obtained.

Informed consent concerning statistical analysis of the data in the school applicants group was obtained in writing from each twin and their parents as part of the application process.

\section{Results}

\section{Maternal associations group (age at first spoken word)}

The results of the stepwise regression analysis were shown in Table 2. Factors affecting the age at first spoken word were sex $(\mathrm{p}<0.0001)$ and motor development $(\mathrm{p}=0.0003)$ at 0.01 significance level. In these cases, females and earliness of sitting with head steady showed a tendency toward earliness for the age at first spoken

Table 2 The results of the stepwise regression analysis for the age at first spoken word

\begin{tabular}{lcc}
\hline & $\mathrm{p}$ & coefficient of determination $\left(\mathrm{R}^{2}\right)$ \\
\hline sex & $<0.0001$ & 0.0205 \\
motor development (sitting with head steady) & 0.0003 & 0.0121 \\
birth complications of mothers or twins & 0.0382 & 0.0039 \\
parity & 0.0535 & 0.0034 \\
age of twins at data collection & 0.0764 & 0.0029 \\
zygosity & 0.0928 & 0.0026 \\
birth order of twins & n.s. \\
maternal age at twin birth & n.s. \\
paternal age at twin birth & n.s. & \\
gestational weeks & n.s. & \\
birthweight $(\mathrm{g})$ & n.s. & \\
\hline
\end{tabular}

Subjects were maternal associations group $(\mathrm{n}=1057)$. 


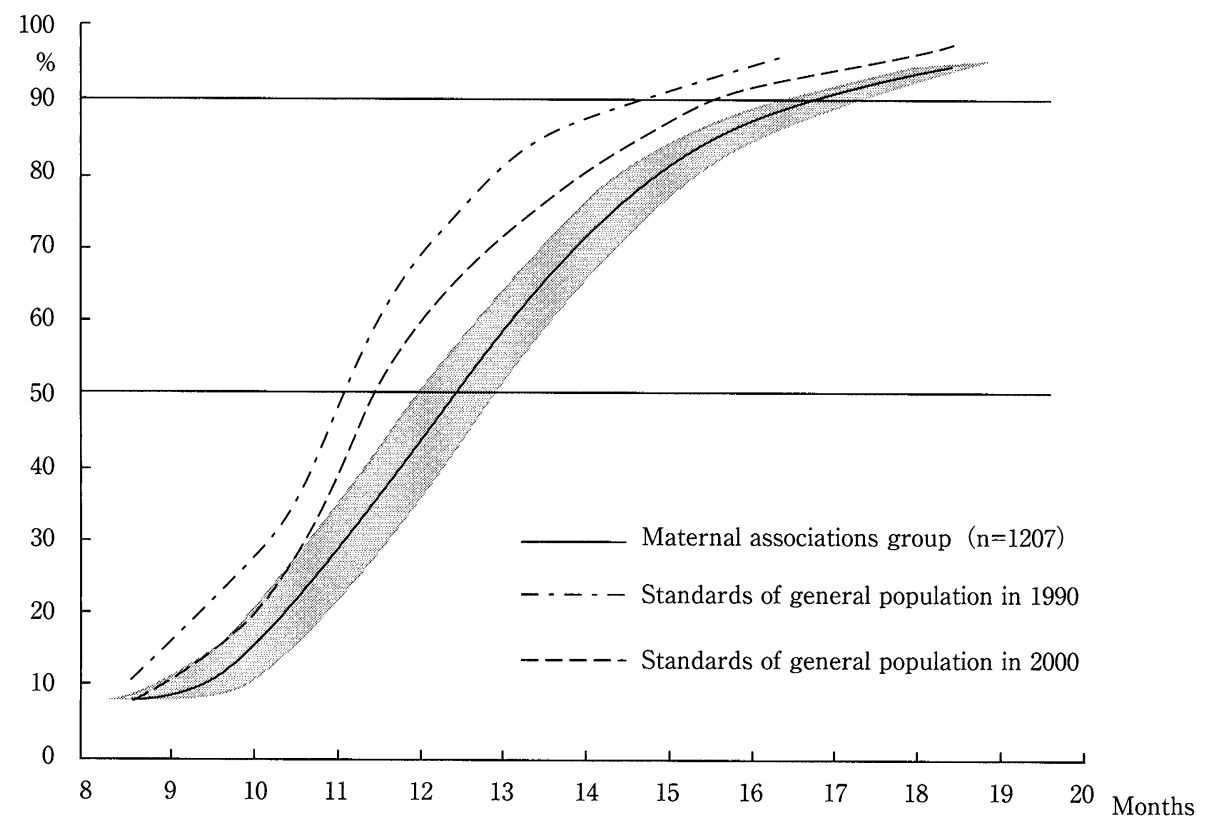

Fig. 1 Cumulative frequency distribution of twins for the age at first spoken word compared with standards obtained from the Japanese general population

word, though the contributions of these factors themselves were not so large. Not significant at 0.01 significance level birth complications $(p=0.0382)$, parity $(p=0.0535)$, age of twins at data collection $(p=0.0764)$, and zygosity $(p=0.0928)$ were also selected. In these cases, no birth complications, multiparity, younger age of twins (recent birth year), and DZ twins showed a tendency toward earliness for the age at first spoken word.

Cumulative frequency distribution compared with general population norms are shown in Figure 1 . Only the range between 8.5 and 18.5 months is presented, which is how general population norms are presented. As mentioned earlier in the methods section, the present data was obtained by month. For example, if mothers answered that the age at first spoken word was 8 months, the data contained information from just
8 months and 0 days to 8 months and 30 days (nearly 9 months). In general, an interval of about one month was considered. Therefore, both the earliest and the latest patterns were presented; thus, the results were shown as area. Compared with general population norms, that in the maternal associations group was about one to two months delayed. Nevertheless, about $95 \%$ of twins had begun speaking one word at 18 to 19 months.

Cumulative frequency distributions according to sex are shown in Figure 2. Males were slightly delayed compared with females.

Mean and median months of the age at first spoken word according to sex and zygosity combination are shown in Table 3. Mean months of age at first spoken word was significantly earlier in females than in males $(p<0.0001)$. This tendency was observed irrespective of zygosity, except 


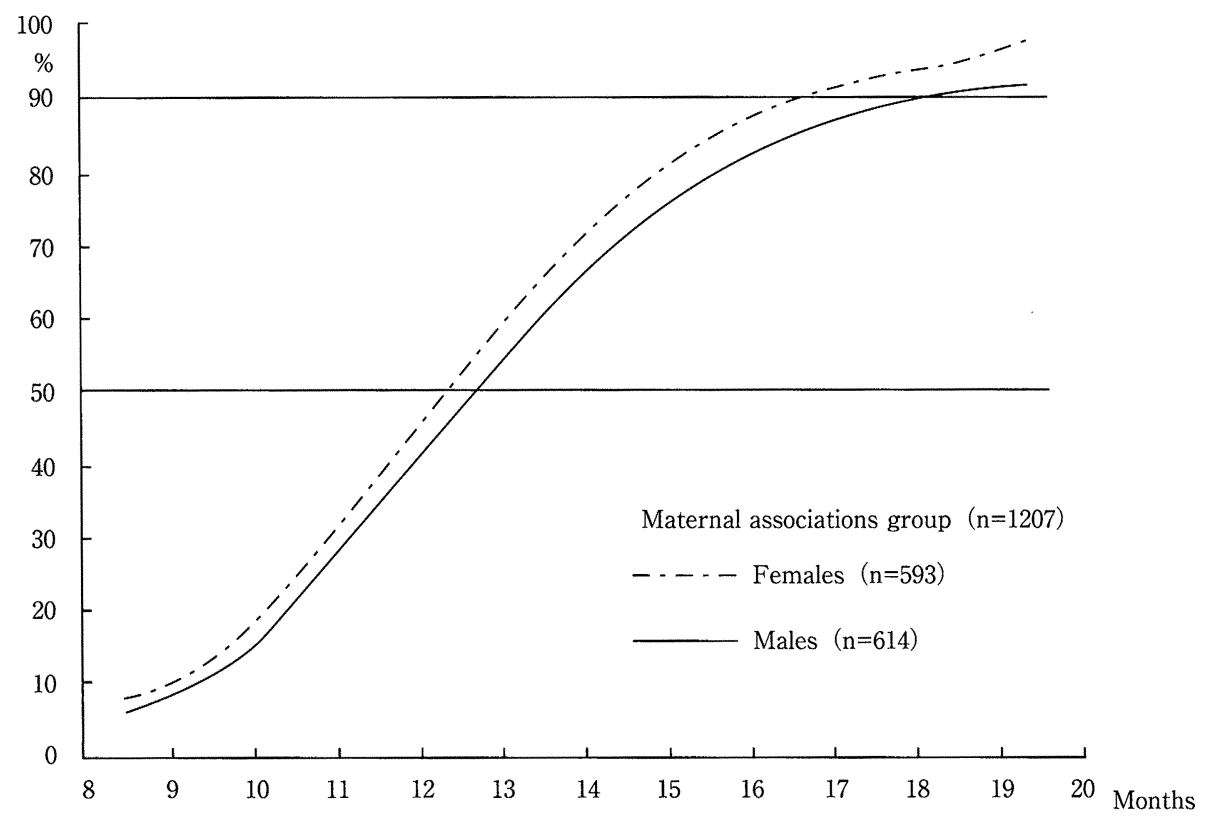

Fig. 2 Cumulative frequency distribution of twins for the age at first spoken word according to sex

Table 3 Mean and median months for the 'age at first spoken word' for the maternal associations group

\begin{tabular}{lcccccc}
\hline & $\mathrm{n}$ (twin individuals) & median & mean & SD & \multicolumn{2}{c}{ sex difference } \\
\cline { 5 - 7 } & & & & Variance & $\mathrm{p}$ \\
\hline MZ males & 319 & 13.5 & 14.7 & 3.8 & & 0.0082 \\
MZ females & 285 & 12.5 & 13.9 & 3.5 & equal & \\
same-sex DZ males & 112 & 14.0 & 14.8 & 4.0 & & \\
same-sex DZ females & 138 & 12.5 & 13.2 & 3.7 & equal & 0.0009 \\
opposite-sex DZ males & 132 & 13.0 & 14.3 & 4.0 & & \\
opposite-sex DZ females & 140 & 12.5 & 13.7 & 3.7 & equal & 0.1894 \\
all males & 616 & 13.5 & 14.6 & 3.9 & & \\
all females & 593 & 12.5 & 13.7 & 3.5 & equal & $<0.0001$ \\
\hline
\end{tabular}

MZ: Monozygotic, DZ: Dizygotic, SD: Standard Deviation

Subjects were maternal associations group.

All males and all females contain twin individuals of unclassified zygosity.

T-test was performed as to sex difference of means.

for opposite-sex DZ. There was no tendency for the language development of males of oppositesex DZ to be more rapid than that of males of same-sex DZ.
2. School applicants group (maternal subjective estimation of their twins' language development)

Maternal estimation of their children's development of language relative to that of contempo- 
Table 4 Answers to the question 'In infancy, was your twin children's language development delayed compared with that of contemporary singletons?'

\begin{tabular}{lcccccc}
\hline & $\mathrm{n}$ (twin individuals) & $\begin{array}{c}\text { not } \\
\text { delayed } \\
\%\end{array}$ & $\begin{array}{c}\text { slightly } \\
\text { delayed } \\
\%\end{array}$ & $\begin{array}{c}\text { considerably } \\
\text { delayed } \\
\%\end{array}$ & \multicolumn{2}{c}{ sex difference } \\
\cline { 6 - 8 } MZ males & 627 & 58.5 & 28.6 & 12.9 & & \\
MZ females & 774 & 75.5 & 18.4 & 6.2 & 47.3 & $<0.0001$ \\
same-sex DZ males & 134 & 73.1 & 18.7 & 8.2 & & \\
same-sex DZ females & 122 & 74.6 & 20.5 & 4.9 & 1.2 & 0.5571 \\
opposite-sex DZ males & 112 & 60.7 & 26.8 & 12.5 & & \\
opposite-sex DZ females & 110 & 73.6 & 18.2 & 8.2 & 4.2 & 0.1222 \\
all males & 966 & 60.9 & 27.2 & 11.9 & & \\
all females & 1101 & 75.4 & 18.4 & 6.2 & 52.5 & $<0.0001$ \\
\hline
\end{tabular}

MZ: Monozygotic, DZ: Dizygotic

Subjects were school applicants group.

All males and all females contain twin individuals of unclassified zygosity.

Table 5 Answers to the question "To what degree was the language development of your twin children alike during infancy?'

\begin{tabular}{|c|c|c|c|c|c|c|}
\hline & n (twin pairs) & $\underset{\%}{\text { no difference }}$ & \multicolumn{2}{|c|}{$\begin{array}{c}\text { slight difference } \\
\%\end{array}$} & \multicolumn{2}{|c|}{$\begin{array}{c}\text { clear difference } \\
\%\end{array}$} \\
\hline MZ pairs ${ }^{1)}$ & 670 & 85.5 & \multicolumn{2}{|c|}{6.1} & \multicolumn{2}{|c|}{8.4} \\
\hline male pairs ${ }^{2)}$ & 299 & 84.3 & \multicolumn{2}{|c|}{7.4} & \multicolumn{2}{|c|}{8.4} \\
\hline female pairs ${ }^{3)}$ & 371 & 86.5 & \multicolumn{2}{|c|}{5.1} & \multicolumn{2}{|c|}{8.4} \\
\hline same-sex DZ pairs ${ }^{1)}$ & 133 & 62.4 & \multicolumn{2}{|c|}{8.3} & \multicolumn{2}{|c|}{29.3} \\
\hline male pairs ${ }^{2)}$ & 70 & 54.3 & \multicolumn{2}{|c|}{12.9} & \multicolumn{2}{|c|}{32.9} \\
\hline female pairs ${ }^{3)}$ & 63 & 71.4 & \multicolumn{2}{|c|}{3.2} & \multicolumn{2}{|c|}{25.4} \\
\hline \multirow[t]{3}{*}{ opposite-sex DZ pairs } & 108 & 55.6 & \multicolumn{2}{|c|}{8.3} & \multicolumn{2}{|c|}{36.1} \\
\hline & & & $\begin{array}{c}\text { males were } \\
\text { delayed }\end{array}$ & $\begin{array}{c}\text { females were } \\
\text { delayed }\end{array}$ & $\begin{array}{l}\text { males were } \\
\text { delayed }\end{array}$ & $\begin{array}{c}\text { females were } \\
\text { delayed }\end{array}$ \\
\hline & & & 5.6 & 2.8 & 26.9 & 9.3 \\
\hline
\end{tabular}

MZ: Monozygotic, DZ: Dizygotic

Subjects were school applicants group.

1) Zygosity difference was significant by $\chi^{2}$ test $\left(\chi^{2}=49.3, \mathrm{p}<0.0001\right)$

2) Zygosity difference was significant by $\chi^{2}$ test $\left(\chi^{2}=34.7, \mathrm{p}<0.0001\right)$

3) Zygosity difference was significant by $\chi^{2}$ test $\left(\chi^{2}=16.3, \mathrm{p}=0.0003\right)$

rary singletons in childhood is shown in Table 4. Significant $(\mathrm{p}<0.0001)$ sex difference was observed by $\chi^{2}$ test (males vs. females; $\chi^{2}=52.5$, $\mathrm{p}<0.0001$ ). About $40 \%$ of mothers of males and $25 \%$ of mothers of females answered that there were varying degrees of delay in language development relative to that in singletons. Considering zygosity, this tendency was obvious with regard to $M Z$ twins.

Maternal estimation of the similarity of language development within twin pairs is shown in Table 5. A significant influence of zygosity on similarity was observed by $\chi^{2}$ test (MZ vs. same-sex DZ; $\left.\chi^{2}=49.3, \mathrm{p}<0.0001\right)$. It can be seen that about $85 \%$ of $M Z$ pairs were regarded to show 'no difference' from their co-twins in terms 
of language development in childhood, whereas $54.3 \%$ of DZ males, $71.4 \%$ of DZ females, and $55.6 \%$ of opposite-sex $\mathrm{DZ}$ were regarded to show 'no difference'. More than $25 \%$ of mothers of DZ twins reported 'clear difference' in development between children. The delay in males was marked in opposite-sex $\mathrm{DZ}$ pairs.

\section{Discussion}

\section{Maternal associations group (age at first spoken word)}

Though the present data was limited to only maternal reports for the age at first spoken word, considerably significant effects of sex and motor development were observed. On the other hand, no effects of birthweight and gestational age were observed. These factors appeared not so influential regarding the age at first spoken word. Recently, using systematic collection of detailed twin data from the Avon Longitudinal Study of Parents and Children, Rutter et al. (2003) concluded that obstetric/perinatal features do not account for the slower language development in twins relative to that of singletons.

As shown in Figure 1, compared with norms of the general population, maternal association groups showed a delay of about one to two months for age at first spoken word. The first possible explanation for this was essential delay of development in twins compared with that in singletons, though the reasons for this delay were unclear. Another possible explanation derives from the difference in the data collection method between the general population and the present subjects. The present data was based on maternal retrospective reports, mainly by means of a mother's memory or records in the "Maternal and Child Health Handbook". It is possible that the higher the age of the twins at data collection became, the more unreliable was the memory of the mother, particularly if she depended only on memory. But regression analysis showed no strong effect of age at data correction on the age at first spoken word, as shown in Table 2. Moreover, no direct correlation was found between age at first spoken word and age of twins at data collection ( $n=1207, r=-0.072$, n.s.). On the other hand, developmental norms presented by the Ministry of Health, Labour and Welfare were determined based on observation during health examinations, performed around the same time throughout Japan, on more than ten thousand subjects. The results were recorded in the questionnaire as binary data of 'possible' or 'impossible', and values were added up according to the real age after birth (Takaishi et al., 1992; Kato et al., 2002). This difference in data collection method can not be adjusted for, and represents a limitation of the present questionnaire survey.

\section{School applicants group (maternal sub- jective estimation of their twins' lan- guage development)}

An effect of sex difference on language development throughout childhood was clearly observed. This tendency was widely recognized in twins as well as in singletons. Males were delayed compared with females. The causes were more complicated in twins in consideration of the effect of their co-twin. According to Garitte et al. (2002), apropos of language development, it is more advantageous for a male twin to have female co-twin than a male co-twin. An effect of the sex difference of the co-twin was not clearly observed in this study, partly because of limited questions.

As shown in Table 4 and Table 5 , both members of MZ male pairs may be delayed to nearly the same degree, with the result that twin pairs 
became relatively similar, whereas $\mathrm{DZ}$ male pairs of twins may be delayed to varying degrees, with the result that twin pairs became dissimilar.

It has been reported that patterns of parentchild interaction and communication have environmentally mediated effects on language and account for twin-singleton differences in language development (Rutter et al., 2003). The present study gathered no data on mother-to-twin interaction in terms of language development.

Language development of twins is very complicated, and is influenced by sex and zygosity in their various combinations. Moreover, the influence of so-called 'twin language' has often been reported (Hay et al., 1987; Bakker, 1987; Dodd and McEvoy, 1994; Bishop and Bishop, 1998; Thorpe et al., 2001). In general twin language is often observed to be used only within certain twin pairs, and it cannot be understood by others. As yet, there is no established definition of twin language. About $40 \%$ of twin pairs show twin language, typically occurring in the second year of life and decreasing considerably over the next 16 months (Thorpe et al., 2001). Twin language has more often been observed in males and MZ pairs, causing delay of language development. According to the results of maternal reports shown in Table $4, \mathrm{MZ}$ males showed the largest delay relative to development in singletons, which finding partly supports the above findings regarding twin language.

Maternal subjective reports may be very informative concerning total language development throughout childhood, as mothers are typically able to observe their twin children more frequently and attentively than anyone else can. As shown in Table 5, language development in childhood was obviously similar between MZ pairs compared with that between DZ pairs, ir- respective of sex combination. Zygosity classification of same-sex twins in childhood was very rare in Japan. Moreover, zygosity misclassification at birth by means of easy placental findings occurred in about $25-30 \%$ of $\mathrm{MZ}$ twin pairs (Ooki et al., 2004). Therefore, mothers of samesex twins often did not know the correct zygosity of their children. Taking these circumstances into consideration, the similarity between $\mathrm{MZ}$ twins, who have identical genetic composition, compared with that between DZ twins, whose genetic similarity is only $50 \%$, slightly suggested a role of genetic background in language development. Dale et al. (1998) reported considerable genetic contribution to language development by performing the detailed genetic epidemiologic twin study of the largest sample based on more than 3000 pairs of twins.

\section{Over the course of this study}

Contrary to the rapid increase of multiple birth rates in Japan, little attention has yet been paid and limited information obtained concerning physical growth, motor and language development of multiples in childhood, and many problems related to the nurturing and rearing of multiples.

The lag in language development of twins behind singletons has been reported many times in western countries (Tomasello et al., 1986; Hay et al., 1987; Akerman, 1987; Akerman and Thomassen, 1991, 1992; Thorpe et al., 2003; Rutter et al., 2003). Though this tendency has been experientially recognized, there existed no objective data on a large subject sample in Japan to demonstrate this phenomenon. In general, three main reasons for delayed development have been suggested: obstetric complications, twinspecific features, and postnatal differences in family interaction. 
The present study consisted of two separate analyses of answers to questions of language development for the two independent samples. Therefore, the results of these respective samples may not be linked directly. This is the most significant limitation of this study. Nevertheless, the two sets of data showed two common results that have often been reported in the language development of twins. Twins tend to lag behind singletons in terms of language development and this tendency is more marked in male twins.

The age of twins in the maternal associations group varied, and not all of them had reached the stage of childhood at which language development is complete. The author used these subjects as a sample that more adequately represents the general twin population, given that the twins of the school applicants group were considered to represent more selection bias with regard to total developmental items including those of language development. The twins in the school applicants group had already completed the basic language development of childhood. Therefore, the author used this group to analyze total language development throughout childhood by means of maternal objective estimation of their children.

According to the interviews with mothers, the following advice was frequently given upon health examinations. 'Because your children are twins, language delay, compared with the development in singletons, is a natural event', or 'Your children will catch up with singletons sooner or later. Therefore, do not worry'. Surely this advice offers temporary comfort to mothers, but provides no essential solution. Mothers may feel anxious over the results of two types of comparison: comparison of twins with singletons and comparison between two their children. Concern about language development is one of the most common and most serious questions about their children that parents, especially those of twins, bring to their pediatricians or public health nurses. Although a substantial proportion of language delays in twins seemed to resolve themselves in the preschool or early school years, no epidemiologic data showing this is available in Japan. According to the present results, surely some twins are delayed, compared with singletons, in terms of language development throughout early childhood. Nevertheless, most of this delay disappears at least by 11 or 12 years of age, which the author and the co-interviewer ascertained in the medical interview with mothers of twins in the school applicants group. By a comparison within twin pairs, about $30 \%$ of $\mathrm{DZ}$ pairs were reported to show a clear difference in language development. In the situation of a medical examination of twins, medical staff should be aware that even within twin pairs, language development can differ considerably.

The present data was limited to normally developed twins for the data collection, and could not show when twins fully catch up with singletons or the prevalence of clinically significant language difficulties in twins. A longitudinal follow-up study of total growth and development of twins, including language development, is essential, and such a study has recently been undertaken by the authors.

In conclusion, the results of present study, using the largest dataset of Japanese twins in childhood, indicated that language development of twins in some respects differs from that of singletons, and that an estimation of language development specifically for twins is necessary for refined maternal and child health care for multiples. 


\section{Acknowledgements}

The author would gratefully acknowledge the help of Toshimi Ooma regarding the analysis of the data. The author would gratefully acknowledge the help of Dr. Noriko Kato of National Institute of Public Health for useful suggestion and information. The author would gratefully acknowledge the help of Norio Yamanaka, the president of Bindeballe Publishing Company, Tsutomu Onodera, the president of Twins and Super Twins Mailing List Japan, Miyuki Sano, the president of the maternal association Twin Dream, and Dr. Yukiko Amau, the president of The Japanese Association of Twins' Mothers, and many other mothers of twins who helped to collect data. This work was supported in part by a Grant-in-Aid from the Ministry of Health, Labor and Welfare of Japan (Chief Researcher, Yuji Okazaki), and by a Grant-in-Aid from the Ministry of Education, Culture, Sports, Science and Technology of Japan.

\section{References}

Akerman BA (1987): The expectation and parentage of twins. A study on the language development of twin infants, Acta Genet Med Gemellol, 36(2), 225-232

Akerman BA, Thomassen PA (1991): Four-year follow-up of locomotor and language development in 34 twin pairs, Acta Genet Med Gemellol, 40(1), 21-27

Akerman BA, Thomassen PA(1992): The fate of "small twins": a four-year follow-up study of low birthweight and prematurely born twins, Acta Genet Med Gemellol, 41(2-3), 97-104

Bakker P(1987): Autonomous languages of twins, Acta Genet Med Gemellol, 36(2), 233-238

Bishop DV, Bishop SJ (1998): "Twin language": a risk factor for language impairment?, J Speech Lang Hear Res, 41(1), 150-160

Dale PS, Simonoff E, Bishop DV et al. (1998): Genetic influence on language delay in two-yearold children, Nat Neurosci, 1(4), 324-328
Day EJ (1932): The development of language in twins, Child Dev, 3, 179-199

Dodd B, McEvoy S (1994): Twin language or phonological disorder?, J Child Lang, 21(2), 273-289

Garitte C, Almodovar J-P, Benjamin E et al. (2002): Speech in same- and different-sex twins 4 and 5 years old, Twin Res, 5(6), 538-543

Hay DA, Prior M, Collett S et al. (1987); Speech and language development in preschool twins, Acta Genet Med Gemellol, 36(2), 213-223

Imaizumi Y, Nonaka K (1997): The twinning rates by zygosity in Japan, 1975-1994, Acta Genet Med Gemellol, 46(1), 9-22

Kato N, Okuno A, Takaishi M (2002): Growth standards of Japanese infant. Research by Ministry of Health and Welfare of Japan in 2000, Kato N and Takaishi M eds., Nihon syouni hoken kyoukai (Tokyo) (in Japanese)

Ooki S, Asaka A (2004): Zygosity diagnosis in young twins by questionnaire for twins' mothers and twins' self-reports, Twin Res, 7(1), 512

Ooki S, Sasaki T, Asaka A (2003): Twin registries in foreign countries: an overview, Jpn J Health \& Human Ecology, 69(3), 90-104 (in Japanese)

Ooki S, Yokoyama Y (2003): Reference birth weight, length, chest circumference, and head circumference by gestational age in Japanese twins, J Epidemiol, 13(6), 333-341

Ooki S, Yokoyama Y (2004): Physical Growth Charts from Birth to Six Years of Age in Japanese Twins, J Epidemiol, 14(5), 151-160

Ooki S, Yokoyama Y, Asaka A (2004): Zygosity misclassification of twins at birth in Japan, Twin Res, 7(3), 228-232

Rutter M, Thorpe K, Greenwood R et al. (2003): Twins as a natural experiment to study the causes of mild language delay: I: Design; twinsingleton differences in language, and obstetric risks, J Child Psychol Psychiatry, 44(3), 326341

SAS INSTITUTE Inc (1997): SAS/STAT Software: Change and enhancement through Release 6.2. Cray, NC: SAS Institute Inc.

Takaishi M, Takano A, Kato N et al. (1992): Growth standards of Japanese infant. Research by Ministry of Health and Welfare of Japan in 1990, Takaishi M eds., Nihon syouni hoken kyoukai (Tokyo) (in Japanese) 
Thorpe K, Greenwoood R, Eivers A et al. (2001): Prevalence and developmental course of 'secret language', Int J Lang Commun Disord, 36(1), 43-62

Thorpe K, Rutter M, Greenwood R (2003): Twins as a natural experiment to study the causes of mild language delay: II: Family interaction risk factors, J Child Psychol Psychiatry, 44(3), 342355

Tomasello M, Mannle A, Kruger AC (1986): Linguistic environment of 1- to 2-year-old twins, Dev Psychol, 22, 169-176

(Received 5. 12, 2004 ; Accepted 10. 1, 2004) 